\title{
Historias y narrativas en la educación infantil
}

Stories and narratives in early childhood education

\author{
Jacqueline de Fátima dos Santos Morais* \\ Universidade Estadual do Rio de Janeiro
}

Resumen Este artículo discute la importancia de la narrativa oral y escrita para el mantenimiento de la tradición y la historia de cada uno de nosotros, en una sociedad que parece valorar más la información que las historias vividas y contadas. Subraya la necesidad, en el colegio, de que los profesores lean cuentos a los niños de educación infantil para desarollar en ellos el amor al mundo de la literatura. El texto también contiene las situaciones encontradas en las escuelas que demuestran el valor de la lectura y la magia que la literatura juega en las vidas de los niños.

PALABRAS-CLAVE: Infancia, Lectura, Narrativa.

Abstract This article discusses the importance of oral and written narrative for the maintenance of tradition and history of each one of us, in a society that seems to valorize the information more than the stories lived and told. It stresses the need, at school, of the teachers to read stories to children from early childhood education to boys and girls love to the world of literature. The text also contains situations encountered in schools that show the value of reading and the magic that literature provides in the lives of children.

KEYWORDS: Childhood, Reading, Narrative. 


\section{¡Cuéntala de nuevo!}

Una conocida historia, nacida en la tradición oral de la vieja Europa, y transformada en texto escrito por Charles Perrault en la París del siglo XVII, es narrada por una profesora en una clase de Educación Infantil.

Sentados en rueda, ojos atentos y bocas entreabiertas, niños y niñas esperan, en silencio casi absoluto, que en el último minuto el desenlace de la historia suceda. ¿Será que el lobo alcanzará a la niña? ¿Habrá quien oiga sus pedidos de socorro?, se preguntan en silencio los pequeños oyentes. Un alivio recorre los rostros infantiles, antes marcados por la expectativa de lo que guardaría la trama de la narrativa. Por fin, un eximio cazador aparece en escena, disponiéndose a salvar a los personajes en peligro. Es la confirmación del triunfo del bien.

Al final de la historia narrada, el valiente héroe recibirá por premio lo que la niña trajo en una cesta para la abuela: torta y jugo. Y todos (o casi todos, si no nos olvidamos del lobo), podrán vivir, por fin, felices para siempre.

Al término de la trama escuchada, un coro de voces disonantes suplica a la narradora: ¡cuéntela de nuevo!

La imagen tejida en nada sorprenderá si el lector o lectora de este texto fuese docente. Ciertamente, durante esta lectura, habrá rememorado otras tantas escenas protagonizadas, ahora por si mismo, en la cual, al final de una narrativa compartida, el mismo pedido en coro era escuchado: ¡cuéntela de nuevo!

Escenas como éstas nos hacen recordar que frente a una buena historia, todo oyente tiende a sentirse contagiado y a desear que no cese de repente la experiencia estética que vive. Delante de un buen narrador o narradora deseamos la continuidad de la historia saboreada por el oído, y nos atrevemos a exigir su recomienzo, pues nos posibilita revivir el sabor ya probado: ¡cuéntela de nuevo!

Es Walter Benjamin que aprendió a "escuchar a contrapelo" las narrativas pertenecientes a la tradición oral, percibiendo en ellas un papel restaurador de la humanidad perdida en la modernidad y desarrollando sobre ellas una escucha sensible, quien nos recuerda que "Contar historias siempre fue el arte de contarlas de nuevo, que se pierde cuando las historias no son más conservadas.” (1996, p. 205)

No hay como discordar de Benjamin. Sin dudas, el arte de narrar siempre estuvo sumergido en las artes de la memoria y de la repetición. Es ella, la repetición, que desde tempos bien remotos ha garantizado la preservación de lo vivido y de lo contado, de las experiencias colectivas e individuales, de la cultura de los pueblos. Desde siempre contamos y repetimos historias, permitiendo que en ellas sobrevivan las experiencias y tradiciones del lugar. Algunas tomaron, sin embargo, a lo largo del tiempo, la forma escrita, pues ésta se tornó, en la modernidad, el supuesto lugar de preservación contra el tiempo y el olvido, no más el recuerdo.

\section{La Odisea}

De las variadas historias que, perteneciendo a la tradición, fueron un día transcriptas en marcas gráficas, una en especial nos llama la atención por posibilitar 
encontrarnos indicios, desde su origen, a respecto de los complejos caminos que transitaron - y aún transitan - la memoria de los hombres y de las mujeres. Esta historia es la de Ulises, personaje nacido en la tradición mítica griega, presente en la narrativa que Homero realiza en La Odisea. El viaje de Ulises puede ser entendido, por la mirada de la dialéctica del esclarecimiento de Horkheimer y Adorno (1985), como la trayectoria de todos nosotros. En este sentido, ella representa la búsqueda del ser humano en construirse sujeto, en encontrar una identidad humana, en preservar, por lo tanto, su historia.

Durante su aventura, Ulises procura escapar de diversos y terribles enemigos, tales como Calipso, Cirne, Polifemo, Cila y Caribde, y de la fruta de Lotus, provocadora del temible olvido. Va, durante su trayecto de victorias y derrotas, reafirmando su identidad como alguien que se pretende sujeto de la historia, alguien que desea, y consigue, construir y reconstruir su destino y, en su nombre, no dejarlo perdido en el reino del olvido. Es en la isla de los comedores de Lotus, de sabor más dulce que la miel, que Ulises vive el desafío que todos nosotros vivimos hoy en la modernidad: librarnos del olvido que apaga nuestros rastros y nuestros hechos. Al comer la fruta del Lotus, algunos de los marineros que acompañan a Ulises son tomados por un estado de letargo, tomados por el olvido y por la destructiva pérdida de la memoria. Es Ulises quien salva sus compañeros al negarse a comer la peligrosa fruta. Teniendo su memoria preservada, salva a todos, rescata sus compañeros y a si mismo.

La odisea de este personaje es emblemática. En ella aprendemos que es la vida humana y cotidiana el lugar donde la historia se hace y rehace. Es en ella que los sujetos entretejen, con invisibles hilos, lo vivido, rememorando el pasado, para así reconstruirse a si mismos, dando a sus propias vidas un sentido de destino. Recordar es, para Ulises, un trabajo de afirmación de la existencia. Recordar, y contar de nuevo.

\section{Recontar historias a los niños}

Pero, como quien cuenta un cuento agrega un elemento... Contar, o mejor, recontar, representa siempre transmitir una vieja historia como se fuese nueva, pues al (re)contar una narrativa, esta acaba por ser modificada por el estilo de quien cuenta, acaba por ser cambiada por la selección de quien narra, por las interpretaciones de quien dice lo que escuchó. Contar es, pues, pasar para adelante una historia que siendo vieja, se torna nueva a cada día por la acción no sólo del entendimiento de quien cuenta, sino también de quien la escucha. Así lo hizo Homero. Así lo hacen los adultos. Así también, los niños.

\section{- Profesora, yo sé contar la historia de Blancanieves. ¿Puedo contarla?}

Las historias, nos dice Benjamin, se mantienen vivas en la memoria del oyente más fácilmente cuando son asimiladas a la propia experiencia, y en consecuencia "más irresistiblemente él cederá a la inclinación de recontarlas un día" (1996, p. 205)

Si hombres y mujeres, de toda y cualquier edad, no son inmunes al flujo de una narrativa cuando esta evoca, y se inscribe, en las experiencias comunes entre narrador y oyente, también los niños no son insensibles a la experiencia narradora, pareciéndonos decir, en el pedido de recomenzar lo contado, que es necesario no permitir que la facultad de intercambiar experiencias a través del lenguaje oral desaparezca. 
- Profesora, ¡cuente de nuevo la historia del lobo feroz!

- ¡Eso! ¡Cuéntela otra vez!

$\mathrm{Al}$ atender el pedido infantil, contamos de nuevo. Pero este recontar produce un tejido textual que es nuevo, pues está impregnado por marcas personales distintivas, que dialogan con el texto guardado de memoria. Este texto que surge no es más una copia fiel del anterior. Es un nuevo texto y, al mismo tiempo, no lo es, pues los hilos de la narrativa recontada son entretejidos por manos que guardan ritmos propios, por voces que mantienen entonaciones singulares, por cuerpos que revelan experiencias originales. Así, es que la narrativa...

no está interesada en transmitir el puro en-si de la cosa narrada como una información o un informe. Ella sumerge la cosa en la vida del narrador para, en seguida, retirarla de él. Así se imprime en la narrativa la marca del narrador, como la mano del alfarero en la arcilla de la vasija. (BENJAMIN, 1996, p. 205)

Narrar historias a los niños es, en cierta forma, entonces, imprimir en el texto y en los propios oyentes, marcas: marcas de la cultura de su grupo, marcas de otros grupos distantes, marcas que desconocemos. $Y$ esta relación entre quien narra y quien escucha, recibe marcas también. (MORAIS, 2002)

\section{Concepción de lectura en la escuela}

Es así, contando y leyendo historias para niños desde bien temprano, que vamos cumpliendo con el destino de todo profesor y profesora: apasionar a sus alumnos y alumnas por el mundo de la narrativa, donde la literatura es una de las formas de su registro escrito. Pero hay otros. Digo apasionar porque creo que es más significativo para hablar de lo que hacemos - o deberíamos hacer en la escuela - que el tan propagado objetivo: desarrollar el hábito de la lectura. Al fin de cuentas, ¿qué es la lectura como un hábito? Edneusa, una alumna de casi seis años, frecuentando el entonces llamado Jardín III de una escuela pública de Rio de Janeiro, nos da pistas para comprender como esa concepción - lectura como un hábito - viene siendo socialmente construida.

Durante una "ronda", actividad que en la Educación Infantil brasileña es diaria, los niños sentados en círculo realizan una discusión colectiva. La temática gira en torno de lo que los alumnos y alumnas piensan que vivirán en el año siguiente, cuando estén inscriptos en la Clase de Alfabetización (CA).

Las llamadas "Clases de Alfabetización" no existian como esclaridad obligatoria en todas las redes de enseñanaza en Brasil. La sistematizacion de la enseñanza de la lectura y escritura fue acurriendo en general al final de la educacion infantil o en la llamada primera serie. Algunas redes de enseñanza, como la de Rio de Janeiro, tenian la clase de alfabetizacion que era el primer año de la escolaridad de la enseñanza fundamental, antes del reglamento atraves de la Ley Ordinaria 11274/2006 . Esta Ley se instituyó como obligatoria a la matricula de los alumnos que tienen seis años de edad,en la Enseñanza Fundamental. En este texto las clases de alfabetización se refieren a lo que actualmente llamamos primer año de Enseñana Fundamental. 
Las respuestas no dejan dudas. Casi la totalidad de los niños afirma que encontrará tareas que sirven para que aprendamos a leer y escribir: copia de palabras y pedacitos (sílabas), dictados para ganar notas, cuaderno para dejar la letra linda, mucho deber de casa para aprender más, y libro de leer y responder. El tono con que van describiendo la serie de ejercicios, aún sin jamás haberlos realizado en aquel espacio escolar, deja claro: los alumnos y alumnas poseían un modelo de aprendizaje de la lengua escrita. Pero, ¿¿de dónde venía? Podemos levantar algunas hipótesis: ¿̇modelos escolares descriptos por parientes cercanos o por vecinos en la presencia de los niños y apuntados como padrón ideal? ¿La vivencia de ejercicios como los citados, propuestos para los niños por familiares o "explicadoras" (profesoras particulares contratadas con la función de "preparar" a los niños para el año siguiente, esto es, la Clase de Alfabetización)?

Más allá de buscar respuestas definitivas, lo que podemos percibir es que desde temprano los niños buscan comprender cómo es o cómo piensan que debería ser la organización del lugar de aprender a leer, creando y apropiándose de discursos socialmente instituidos, reproduciendo en alguna medida las concepciones escolares hegemónicas. Y las respuestas no dejan dudas: tornando el aprendizaje de la lengua escrita un hábito.

- Yo acá, en la CA, voy a aprender sí o sí. Yo voy a aprender a leer y escribir. - dice Edneusa, en el medio del barullo de otras tantas voces.

- ¿Por qué? ¿Aquí no se aprende? - pregunto.

Todos, sin excepción, responden que sólo van aprender sí o sí a leer en el año siguiente, cuando estén en la CA. Pedro Henrique intenta socorrer a la profesora:

- Es que aquí aprendemos un poquito, ¿no es cierto?

- Eso mismo - confirma Edneusa - un poquito. En la CA vamos a aprender más porque vamos a tener un horario para leer, si no, no nos acostumbramos y no aprendemos.

Reglas, horarios, formas disciplinares, si no, no nos acostumbramos y no aprendemos. Hegemónicamente, el aprendizaje de las narrativas escritas es visto como la adquisición de un hábito (MORAIS, 2010).

En contramano de esta concepción, este aprendizaje pode ser visto como algo que, más que implicar un hábito, implica pasión. Aprender a leer historias sería, pues, una acción cotidiana apasionada. No leemos Carlos Drummond de Andrade por hábito o Clarice Lispector por disciplina. Leemos, deseamos leerlos, por la seducción que estos autores provocan, por la fantasía que alimentan, por la promesa de un encuentro marcado con un tiempo y un lugar: el de la narrativa.

Si las narrativas escritas nos invitan a un encuentro, también los textos orales nos llaman, especialmente aquellos que constituyen las formas arcaicas de saber. Leyendas, cuentos, poemas, cordeles ${ }^{1}$, almanaques, proverbios, adivinanzas, rezos, chistes, fórmulas mágicas, todos textos pertenecientes a la tradición oral que, más que leídos, son guardados de memoria. Todos son textos que tenemos en la memoria, no porque delimitamos un ritual para apropiarnos de ellos, sino porque de ellos dependió, en algún momento, el éxito en nuestro cotidiano. 
- Profe, ¿usted sabe lo que la banana le dijo al tomate?

Como decimos en portugués "decoramos" (memorizamos) textos, los sabemos "de corazón", pues, como resalta el sentido etimológico de esta palabra: ponemos textos en el fondo del corazón para de allí retirarlos en algún momento especial. No sólo los adultos proceden de esta forma, sino igualmente nuestros alumnos y alumnas, independientemente de la edad que tengan, pues no son extranjeros a la cultura local, sino impregnados de su tiempo y de su lugar.

- Tienes que dar tres saltitos y entonces el hipo se va.

Fue lo que le escuché cierto día a un aluno de cuatro años recomendarle a otro de cinco, que estaba hacía ya mucho tiempo con un hipo intermitente. Después escuché al niño decirle nuevamente al primero: ¿Viste? El hipo se cayó al suelo.

La escuela, al desconsiderar las diferentes lecturas que el mundo provoca, como lectura, construye una serie de situaciones pedagógicas donde lo que estará en juego es el cuerpo, la concentración, el movimiento de los ojos y de la boca, y no lo que de hecho importa: la pasión, el deseo, el sentido. De esta forma, la lectura se transforma sólo en el desarrollo un hábito. Se transforma en un proceso de docilización de los cuerpos.

Para comprender este proceso que es históricamente forjado, podemos recorrer a Michel Foucault, pues sus textos nos ofrecen pistas - especialmente en Vigilar y Castigar (1986) - sobre lo que ocurre con los sujetos en las escuelas, más allá de apuntar razones del por qué eso sucede. Foucault nos puede ayudar a comprender que el discurso de Edneusa es forjado socialmente y este discurso la penetra: En la CA vamos a aprender más porque vamos a tener un horario para leer, si no, nos acostumbramos y entonces no aprendemos.

El aprendizaje de la lectura es visto por los niños, porque así también es visto por la sociedad, como una actividad que necesita de la regulación del tiempo individual, pues para aprender es necesaria la repetición. Aprender es, por lo tanto, un acto que se inscribe en la actividad de repetición en las horas que van y vienen: vamos a tener un horario para leer.

En esta situación, la repetición, más que una necesidad generada por los intereses de los sujetos, es como una demanda externa creada y creadora de verdades incontestables: aprende apenas quien repite. Y repite porque desarrolla el hábito. Los niños en sus actividades cotidianas sienten necesidad de hacer de nuevo, de repetir lo que fue experimentado, solicitar la copia de lo que fue vivido. $Y$ en estos casos nunca es para vivir mecánicamente lo antes vivido. Hay siempre en la repetición buscada por los niños la construcción de nuevos sentidos, de sentidos revigorizados, resignificados. Por eso, ellos piden para que la vieja historia sea repetida: jcuéntela de nuevo!

Pero, ¿qué tipo de historias los niños nos piden que sean nuevamente contadas y contadas? ¿Acaso este público utilizaría criterios semejantes a aquellos que, en general, usan los adultos para definir qué libros pueden/deben ser leídos/escuchados por los niños pequeños? La aproximación al grupo de sujetos, niños y niñas, pertenecientes a la faja etaria que comprende la Educación Infantil, ha mostrado que, de 
creer en esta idea, tomaríamos como verdad el borramiento de estos sujetos, de sus experiencias ya vividas.

Los motivos que llevan a los adultos a indicar para determinada faja etaria ciertos libros y no otros no son difíciles de ser enumerados. Encontramos fácilmente críticos literarios que definen los textos que mejor pueden ser comprendidos por alumnos y alumnas de edad definida a priori. Las explicaciones que justifican la entrada de ciertos títulos y no de otros se plantean en el campo del tamaño del texto - breve, si es para un público infantil, - del colorido de las imágenes, pues sin colores los pequeños no se interesan, - de la temática de la narrativa, predominantemente siendo compuesta por la vida de animales.

Tantas veces este discurso es dicho que se transforma en verdad. Entonces, creemos con naturalidad que niños y niñas de menos de seis anos se desinteresan por largos textos o por ciertos temas. Si estos críticos iluminados están correctos, ¿cómo explicar, entonces, la experiencia que vivió Elaine en su clase con niños de cinco años? La narrativa de esta profesora habla por si misma:

Una aprende en el (curso) normal y en el (curso) adicional que el niño pequeño sólo tiene que dibujar, recortar y ir para la casita de muñecas. Tener contacto con el libro sólo si fuese de dibujos bien grandes y coloridos, y preferencialmente sin texto. Conmigo era diferente. Yo percibía que mis alumnos adoraban escuchar historias. Y yo, entonces, les leía. Un día resolví leerles "O Menino Maluquinho". Hubo una gran confusión en la escuela. Me decían que "O Menino Maluquinho" no era adecuado para mi clase, que los iba a desconcentrar, que la clase iba a tornarse un caos... ¿ ¿sabes lo que hice? Les leí el libro enterito, así, en capítulos, como en una novela. Nadie se movía mientras yo leía. Esa historia de que niño pequeño sólo quiere saber de dibujar... sólo si fuese de profesora a la que le no gusta leer.

Niños pequeños y largas narrativas parecen haber sido, desde siempre, mundos apartados, mundos que jamás se encontraron porque estaban situados en lejanas fronteras. La experiencia que los niños vivían en la edad media prueba lo contrario. Naturalizamos y reproducimos una creencia que, de tantas veces repetida, se transformó, finalmente, en consenso: a los niños de tierna edad sólo les gusta leer textos pequeños. No es posible, sin embargo, olvidarnos de que esta supuesta verdad carga y engendra una concepción de sujeto y de aprendizaje, de experiencia y de lengua, de historia y de infancia. Al creer en esta visión hegemónica tendríamos verdades como: es parte de la naturaleza infantil, de la constitución de su pensamiento, la poca concentración que supuestamente demuestran en la audición de textos largos. Con esto, a los niños pequeños, para su propio bien, les resta solamente escuchar cuentos breves bajo pena de que nada comprenderán, siendo infructífero el emprendimiento.

Pero lejos de estas divergencias, los niños pequeños, desde hace mucho dispersos en diferentes localidades, siempre estuvieron al lado de los adultos, experimentando el encuentro con las voces que compartían sus aventuras del día, para nada breves narrativas. En las frías noches de luna, en medio de los hombres de la comunidad, niños de todas las edades - sobrevivientes de un mundo inhóspito y peligroso, sumergido en fiebres, enfermedades contagiosas, hambre y violentas guerras - mezclados con 
los hombres también sobrevivientes, escuchan el tejer de lo dicho, muchas veces en rueda delante del fuego. Los niños que sobraban de la selección hecha por el tiempo, por el hambre y por las enfermedades vivían entre adultos, en un mundo sin división por edades, nos cuenta Philippe Ariès (1978). A estos adultos, también sobrevivientes de una sociedad medieval, se juntaban otros, y allí, en el medio de la rueda, en torno al fuego, contaban sus aventuras y desventuras del día. Los hombres narraban sus historias acompañados de cerca por pequeños ojos, sin derecho, aproximadamente hasta el siglo XVII, a una vida de infancia (¿lo tienen hoy?). Estos niños y niñas seguían las huellas de las experiencias ajenas, tornándolas suyas por la incorporación y resignificación de las historias escuchadas. El mundo adulto y el mundo infantil se tornaban un mundo común y nadie suponía que aquellos pequeños no tenían concentración suficiente para estar allí, escuchando las narrativas tantas veces extensas.

Hoy, en el mundo de la industria librera, y permeando la formación de cada uno y una de nosotros, las historias son rígidamente clasificadas por faja etaria. Hay títulos que supuestamente se prestarían más eficientemente a un público más joven. Otros que serian adecuados a un grupo de más tierna edad.

La situación por mí presenciada en la biblioteca de la escuela donde trabajo para alumnos y alumnas de la Enseñanza Fundamental, es ejemplar para comprender como las clasificaciones aparentemente naturales y facilitadoras para el lector, pueden provocar efectos contrarios.

Somos cerca de 20 alumnos y alunas, además de 3 adultos en la biblioteca, un lugar de espacio reducido, como grande parte de las bibliotecas que existen en este país. Los niños se amontonan entre los estantes. Es hora de leer y elegir libros para préstamos, hora de silencio y respeto. Ellos, en nada siguen las reglas supuestamente evidentes de utilización de aquel espacio, hablando en voz alta y viviendo disputas por ciertos títulos. La bibliotecaria, suponiendo que todo esto sucedía por no haber informado a los niños como la biblioteca estaba organizada, resuelve iniciar una explicación:

- Miren, voy a explicar una cosa muy importante. Atención. Una biblioteca es un lugar organizado. Los libros no son guardados de cualquier forma. Aquí están los libros que ustedes no pueden llevar para casa. Son libros sólo para consulta: enciclopedias y diccionarios. Aquí están los libros de literatura infantil. Estos son los libros para ustedes.

Al escuchar la explicación de la funcionaria, Ariel retruca:

- Pero yo no soy del infantil. Yo soy del primer año.

Los libros, en silencio, esperan el tiempo en que los propios niños puedan elegir que leer, sin definiciones a priori. Y parece que este tiempo ya se encuentra anunciado.

A pesar de la vasta publicación en el área de literatura, aún sabemos muy poco sobre lo que mueve a un niño en dirección a determinado texto y no a otro. Y porque no sabemos, creamos reglas y verdades que desconsideran a los sujetos reales: los niños y niñas, con sus historias, sus experiencias, sus formas de vivir y de ser. ¿Cómo cada niño construye el sentido de cada texto con el que se relaciona? ¿Cuáles 
son los efectos que la experiencia narradora causa en cada uno, en cada una? Al buscar pistas sobre lo que implica la comprensión de estas cuestiones, es preciso tener en cuenta que en la escuela tenemos una comunidad lectora - entendiendo el concepto de lector, inspirado en Paulo Freire, como todo aquel que da sentido a lo que vive, al mundo alrededor. Así como en las comunidades primitivas, donde los textos eran oralizados, en la Educación Infantil buena parte de los textos también lo son. Y son ricos especialmente por ser textos orales, por ser parte de la tradición oral.

Así podemos entender que "el narrador retira de la experiencia lo que cuenta: su propia experiencia o la relatada por los otros. $\mathrm{E}$ incorpora las cosas narradas a la experiencia de sus oyentes." (Benjamin, 1996: 201). Así hacían los antiguos campesinos y los marineros viajantes; así siempre lo hicieron las mujeres a lo largo de la historia, las abuelas, tías, madres, profesoras... mujeres que ponían a los niños en frente de su cuerpo e iniciaban largas e intrincadas historias. Así lo hacen los griós ${ }^{2}$ y los indios ancianos, todos maestros en el arte de narrar, todos sabedores de que el narrador es alguien que sabe dar consejos, que sabe "hacer una sugerencia sobre la continuación de una historia que está siendo narrada" (Benjamin, 1996, p. 200), que sabe compartir la substancia viva que teje lo dicho: sabiduría.

Aquí, en el preescolar, nadie más conversa. Una acaba sintiéndose muy sola. No da tiempo de intercambiar, de compartir, porque no hay hora para eso. Es sólo dar aula, hacer actividades, escribir informes. Así, el trabajo del profesor se torna mucho más difícil. A mí me parece que una, en el preescolar, debía encontrarse todas las semanas para intercambiar, para hablar de lo que está haciendo. Entonces yo iba a poder escuchar también lo que el otro está haciendo. Pero hoy, el profesor no tiene tiempo ni de respirar. (Adriana, profa de Educación Infantil de la red pública)

No sólo los niños necesitan de espacios colectivos de diálogo, espacios de narrar y de escuchar. También nosotros, profesores, precisamos de una comunidad con la que podamos dialogar, una comunidad solidariamente constituida.

\section{La narrativa vivi una crisis?}

En la Educación Infantil se reproduce, no raras veces, la lógica presente en los demás segmentos de la Educación Fundamental: propuestas pedagógicas innovadoras, proyectos pedagógicos impuestos bajo discursos aparentemente democráticos; evaluaciones de todo tipo que permanecen bajo la lógica única de la medición y clasificación, anticipando para la Educación Infantil la lógica con la cual los alumnos y alumnas se depararán en las etapas escolares siguientes; libros didácticos impuestos a la Educación Infantil vaciados de saber y sabor; cursos de formación a distancia, distancia cotidiana del otro; leyes, pareceres, artículos; fracaso escolar; formación profesional precaria; falta de personal; exceso de alumnos por clase; bajos salarios; sueños, desprestigio, deseos... ¿Qué es lo que vivimos hoy en las escuelas: acontecimientos? ¿Catástrofes? ¿Ruinas?

Parecen amontonarse bajo nuestros pies parcelas fragmentadas de lo vivido a diario. Atónitos, como Angelus Novus, figura enigmática de la pintura de Paul Klee, no sabemos cómo proceder frente de lo que nos va aconteciendo. ¿Detenernos para 
recoger los fragmentos y, quién sabe, reconstruir las imágenes escindidas? ¿ ¿Seguir adelante, ajenos a los acontecimientos que se acumulan delante de nosotros?

Tal como la figura de Klee, nos sentimos impelidos a seguir adelante, dejando un pasado que sabemos habitado por nuestra presencia, por nuestros sueños, por nuestros deseos, nuestras marcas, que más que producidas individualmente, fueron y son producciones colectivas. Nuestras marcas poseen rasgos de otros que nos marcaron.

Adriana, al hablarnos de la lógica que parece imperar hoy en las escuelas el distanciamiento, el individualismo, la soledad - nos dice algo también sobre el deseo que es suyo, mas que también es de todos los profesores y profesoras de la Educación Infantil, de romper con esta lógica: "Me parece que una debía encontrarse todas las semanas para intercambiar, para hablar lo que está haciendo."

Adriana parece saber que su identidad como docente sólo se hace con la presencia del otro; que es este otro quien la ayuda a verse y pensarse. Adriana sabe que para ser narradora es preciso tener a su lado una comunidad de oyentes y hablantes, que es preciso tener en quien imprimir las marcas de su experiencia, y en contrapartida, tener quien le imprima las suyas, así como el alfarero, que al hacer la vasija en arcilla, deja sus digitales, marca de su vida y de su trabajo. Adriana consigue, diferentemente del Angelus Novus de Klee, no darle las espaldas a las ruinas que crecen bajo sus pies.

Pero Adriana denuncia la falta de tiempo. Si parece no haber tiempo en una sociedad dominada por la rapidez y por la burocracia, es preciso crear espacios alternativos donde el tiempo se torne aliado de todos nosotros, un tiempo lento, un tiempo de hilar, un tiempo donde el diálogo no exprese sólo un breve recado, mas donde las experiencias de quien habla puedan encontrarse con las de quien escucha, de manera que quien escucha esté en compañía de quien narra (Benjamin, 1996, p. 213). Creo, como Adriana, que eso es posible. Es posible soñar proyectos apoyados en la pedagogía de la esperanza y de la posibilidad, inspirados en Paulo Freire, y ofrecer nuestros sueños a quien quiera soñar con nosotros. Y no faltan profesores y profesores que poseen como horizonte la utopía de una escuela narradora.

Si la sabiduría, como cree Benjamin, parece adormecida en una sociedad pautada por la rapidez de la información, es preciso despertarla y hacerla vivir.

Compartir con Walter Benjamin sus preocupaciones es más que afirmar una constatación: "el arte de narrar está declinando". Lo que queremos, al afirmar la crisis en que viven todos aquellos y aquellas que hoy se encuentran bajo el signo de la modernidad (o posmodernidad, como quieren algunos), es pensar cómo podemos soñar una nueva forma de sociabilidad. Y más: que podemos imaginar formas de estar en la escuela que rompan con la lógica dominante.

Son cada vez más raras las personas que saben narrar debidamente. Cuando se pide en un grupo que alguien narre alguna cosa, el malestar se generaliza. Es como si estuviésemos privados de una facultad que nos parecía segura e inalienable: la facultad de intercambiar experiencias. (1996, p. 197-198) 
¿Qué pistas (Ginzburg, 1991) podemos recoger en nuestro cotidiano que nos permitan desconfiar de lo que afirma Benjamin? ¿Qué movimientos contra-hegemónicos invisibles están presentes en el cotidiano de la vida humana, especialmente en el de las escuelas, que nos dan indicios de que la narrativa no está "en vías de extinción", a pesar de vivir una seria crisis? (BENJAMIN: 1996, p. 197)

Cursos de contadores de historias se multiplican por todo el país, creciendo el número de aquellos que buscan el encantamiento con las historias populares, especialmente las de tradición oral. Numerosos investigadores se preocupan hoy por escuchar las memorias y experiencias de quien vivió los acontecimientos, desconfiados de que la historia oficial precisa ser cepillada a contrapelo, lo que sólo es posible cuando emergen de los acontecimientos otras voces que no son apenas las de los supuestos héroes. Grupos de ayuda de todo tipo, oyentes a veces anónimos. Ruedas de lectura. Contadores de historias... La misma sociedad que produce el silenciamiento produce, contradictoriamente, múltiples formas de romperlo.

\begin{abstract}
¿Quién sabe contarnos una historia? Yo siempre les pregunto a mis alumnos quién quiere contar una historia. Yo no soy la única que sabe contar. Ellos tienen muchas historias interesantes, aunque tengan tan corta edad. Yo llamo también a las madres para contar o para leer una historia. Aprendí a hacer eso con un aluno mío del preescolar. Él vivía reclamando que yo no los dejaba hablar, que sólo yo contaba historias. Fue de ahí que yo aprendí. Aquí, en mis grupos ahora, todo el mundo tiene derecho de contar. (Amanda, prof ${ }^{\mathrm{a}} \mathrm{de}$ Educación Infantil de la red pública)
\end{abstract}

\title{
Derecho de contar... ¿Utopía o posibilidad?
}

La experiencia es la fuente de la que se socorren docentes y educandos. Es en ella, en el suelo de la experiencia, que profesores y profesoras, alumnos y alumnas buscan construir su identidad y humanidad. Las experiencias que cada profesor y profesora escuchan en el cotidiano, dentro y fuera del espacio escolar, se encuentran con las propias y con las de otros tantos que ya pasaron por sus vidas, muchos de los cuales son narradores que no pueden más ser distinguidos por el nombre. Se transformaron en recuerdos anónimos. Reminiscencias sin fechas. Pero se encuentran en las memorias y se presentificam cada vez que son evocados.

Son múltiples las experiencias que cada profesor y profesora poseen, experiencias que podemos comprender no apenas como científicas, tal como Kant las entendía, mas en una dimensión de mayor complejidad y totalidad (Morin, 1995). Fundadas y enraizadas en las múltiples dimensiones de vida de cada docente, las experiencias pueden ser artísticas, religiosas, amorosas, literarias, sexuales, libertarias, silenciadoras.... Si son múltiples las experiencias, son innumerables las historias en potencial que habitan cada docente. Historias que por no reducirse a vivencias individuales, poseen aura y dejan marcas en el oyente.

Si para Benjamin la modernidad trae la lógica de la mediocridad de las experiencias humanas, podemos osar polemizar una vez más, con él, pues, que el declive de la experiencia humana colectiva y la ruptura de su contenido libertador, son reencendidos a cada día en espacios que se abren y que son, siempre, colectivos. Estos movimientos, sin embargo, aparecen poco iluminados y, por lo tanto, poco visibles a la 
mirada desatenta. Pero existen. Y son innumerables. Si el choque de la modernidad, de la alienación, del silenciamiento, nos golpea diariamente, el encuentro con el otro puede salvarnos del aniquilamiento. $Y$ así vemos surgir aquí y allí lugares de encuentro, lugares de reencuentro, lugares donde memoria, palabra y prácticas pueden ser compartidas entre todos. Lugares de hacer y de ser. La dificultad de narrar en una sociedad que doma la palabra, crea la exigencia de nuevas formas de hacer y de contar. Y este contar acaba siendo, por exigencia de un tiempo dicho moderno, recortado, discontinuo, frágil, siempre amenazado por el olvido. Necesitamos, entonces, osar afirmar el lugar de la Educación Infantil como un lugar, en principio, de narrativas, de memorias docentes y discentes.

El cotidiano de las y en las escuelas nos muestra que la experiencia en la sociedad moderna no desapareció por completo. Acontece a cada día, mas está escondida, buscando revelación. Y es a través de la rememoración de las propias experiencias, de las que se vive y de las que se vivieron, que la ruptura con lo que numerosas veces nos tornamos (sujetos autómatas, vaciados de voz, de autoría) puede acontecer.

Lo que percibimos es que cada profesor y profesora de Educación Infantil hoy busca no más la voz autoritaria de un especialista que le diga qué y cuándo hacer, usando para eso su abarcadora palabra interpretativa. Antes que eso, los y las docentes quieren la palabra que posibilite la circularidad de los discursos de todos y la materialización de las prácticas docentes concretas. El lugar de quien dice, quieren hoy profesores y profesoras, debe ser un lugar móvil, y no más petrificado por las verdades del conocimiento denominado científico por quien lo trae. El lugar de quien habla, donde tantas veces se transforma en el lugar de la legitimación de un único discurso, en el lugar del ejercicio del poder, en el lugar de la verdad única, necesita recuperarse como lugar de quien se permite vivir la inseguridad, la errancia, la duda, el aún-no-saber (Esteban, 2001). Lugar de la provisoriedad y del inacabamiento. Desean esto todos los que ya participaron de cursos de "capacitación" y formación docente y experimentaron allí la sensación de verse como tablas rasas, vaciados de saber y de experiencias comunicables.

\begin{abstract}
Yo no voy más a ningún curso dado por la Secretaria de Educación. Ellos hablan un montón de cosas, dicen que tenemos que hacer esto y aquello. Parece que una está asumiendo un grupo por primera vez y ellos son los que saben como dar clase en el Jardín. Ahora, queda tan claro que nadie sabe qué hacer de verdad... Ahí acaba que yo gano mucho más en la hora del cafecito, cuando nos quedamos conversando con las colegas, viendo lo que de verdad ellas hacen. Ahí cada una puede hablar sobre lo que ha hecho en el Jardín, sin miedo de parecer tradicional o entonces constructivista demás. (Irene, profa de la Educación Infantil de la red pública)
\end{abstract}

Quien habla al otro trae sus verdades y crea, no raras veces, estrategias de convencimiento que, en gran medida, excluye al otro con el que no coincide. Al contrario de esto, el lugar que queremos para la educación, es el de la narrativa de todos para todos, es el lugar del discurso plural que se contrapone al discurso único, legitimado por el lugar que ocupa el académico famoso que guiará el grupo, el iluminado y autorizado por su formación escolar. 


\section{Consideraciones finales}

Benjamin, al referirse a los narradores, afirma que estos tradicionalmente eran vistos como personas que venían de lejos, y que por haber viajado, tendrían mucho para contar. "Pero también escuchamos con placer al hombre que ganó honestamente su vida sin salir de su país y que conoce sus historias y tradiciones." (BENJAMIN: 1996, p. 198-199)

Los niños y niñas escuchan con placer las experiencias que sus colegas les cuentan, pues estos oyentes-narradores comparten una colectividad, de experiencias comunes, lo que torna lo dicho comunicable por uno de ellos y, en contrapartida, comprensible para el otro. La relación que se establece es dominada por la necesidad de conservar y compartir lo que es narrado. Ambos saben que la narrativa que uno comparte con el otro no es sólo producto de su voz, sino de todo lo que fue vivido y aprendido a lo largo de la vida, aunque tan corta.

Los espacios potenciales de narración de los docentes y niños están siendo substituidos por espacios de información. Las reuniones de Consejo de Clase o las de planeamiento son algunos ejemplos de este desplazamiento, mas podríamos citar muchos otros. La Educación Infantil puede ser el espacio de la narrativa donde los profesores y profesoras socialicen sus quehaceres pedagógicos, creando, por ejemplo, colectivamente sus materiales didácticos, permitiendo en este hacer conjunto, reencender los puentes entre pasado y presente, individuo y colectividad, producción y recreación.

Todos los hombres y mujeres producen experiencias que, silenciadas, mueren en el olvido. Sin embargo, si despertadas, dejan rastros por donde otros pueden pasar, iluminando caminos de los que otros pueden servirse, ofreciendo pistas para nuevos viajantes.

Soñamos y proyectamos tiempos que, queremos, sean de respeto, de dignidad, de derechos. Tiempos que no aniquilen los recuerdos de quien vivió, que no borren los rastros de quien soñó, que no silencien los dichos de quien osó pronunciar palabras raras. Tiempos en que cada profesor y profesora pueda, en el ejercicio de su oficio de enseñar, encontrar dignidad y respeto. Tiempos donde un cierto pedido no caiga en el olvido: cuenta de nuevo ${ }^{3}$.

\section{Referências}

ARIÈS, P. História social da criança e da família. Rio de Janeiro: Zahar, 1978.

BENJAMIN, W. Ensayos Escogidos. Ed. Sur, Buenos Aires: 1996.

ESTEBAN, M. T. O que sabe quem erra? Reflexões sobre avaliação e fracasso escolar. Rio de Janeiro: DP\&A, 2001.

FOUCAULT, M. Vigilary castigar. Madrid: Siglo XXI Editores, 1986.

FREIRE, P. Pedagogia da esperança. Rio de Janeiro: Paz e Terra, 1993.

GINZBURG, C. Mitos, emblemas e sinais: morfologia e historia. São Paulo: Companhia de las Letras, 1991.

HOMERO. Odisséia. São Paulo: Ediouro, 2009. 
HORKHEIMER, M.; ADORNO, T. Dialética do esclarecimento. Rio de Janeiro: Zahar, 1985.

MORAIS, J. de F. dos S.. Histórias e narrativas na educação infantil. In: GARCIA, R. L. (Org.). Crianças, essas conhecidas tão desconhecidas. Rio de Janeiro: DP\&A, 2002, p. 81-101.

. Alfabetização: concepções e imagens de ensino, aprendizagem e língua no cotidiano escolar. In: PLETSCH, M. D.; RIZO, G. (Org.). Cultura e formação: contribuições para a prática docente. Seropédica: Editora da UFRRJ, 2010.

MORIN, E. Introdução ao pensamento complexo. Lisboa: Instituto Piaget, 1995.

PERRAULT, C. Contos de Perrault. Belo Horizonte: Editora Itatiaia, 1989.

\section{Notas}

\footnotetext{
${ }^{1} \mathrm{~N}$ de $\mathrm{T}$ : La literatura de cordel es un género literario popular brasileño, escrito frecuentemente en forma rimada, originado en relatos orales y posteriormente impresos en folletos. El nombre surge de la forma como tradicionalmente los folletos eran expuestos para la venta, colgados en cuerdas o hilos. Los autores (cordelistas) recitan los versos de forma melodiosa e animada, a veces acompañados de guitarras, para conquistar a los posibles compradores de estos folletos con sus versos.

${ }^{2} \mathrm{El}$ término Griot (griô) denomina a aquel que transmite oralmente la tradición histórica y cultural del pueblo africano.

3 Traducción: Silvina Julia Fernández.
}

* Professora Doutora da Universidade do Estado do Rio de Janeiro, São Gonçalo, Rio de Janeiro - Brasil.

\section{Correspondência}

Jacqueline de Fátima dos Santos Morais - Universidade do Estado do Rio de Janeiro, Faculdade de Formação de Professores. Rua Francisco Portela, 1470, Patronato, CEP: 24435-005 - Sao Gonçalo, Rio de Janeiro - Brasil.

E-mail: jacquelinemorais@hotmail.com

Recebido em 14 de dezembro de 2012

Aprovado em 07 de abril de 2013 